\title{
Summary of the International Scientific Conference "Energy-21: Sustainable Development And Smart Management" September 7-11, 2020 Irkutsk, Russia
}

\author{
N.I. Voropai*, V.A. Stennikov
}

Co-chairmen of Program Commitee of the conference

Melentiev Energy Systems Institute of Siberian Branch of Russian Academy of Sciences, Irkutsk, Russia

The International Scientific Conference "energy-21: sustainable development and smart management" was held in Irkutsk, Russia, on September 7-11, 2020. The Conference was organized by the Melentiev Energy Systems Institute SB RAS with the financial support of the Russian Foundation for Basic Research (RFBR) and with the participation of the Global Energy Interconnection Development and Cooperation Organization (GEIDCO), the Forum of Gas Exporting Countries, and the Global Energy Association.

Over 170 attendees from 18 foreign and 69 Russian organizations from 8 countries (Russia, Qatar, China, Japan, Republic of Korea, Vietnam, Mongolia, Germany, Azerbaijan, and Uzbekistan) took part in the event. The participants presented more than 130 papers.

The Sessions of the Conference focused on the following main areas:

1. Transforming smart energy systems

2. Advanced energy technologies: environmentally friendly and resource-saving energy, renewable energy sources.

3. Eastern vector of Russia's energy strategy: current state, look into the future.

a. World energy markets and international cooperation.

b. Development of the economy, the energy sector (and energy industries) of the Russian Federation and its eastern regions.

c. Local power supply systems in the East of the Russian Federation.

4. Interstate power interconnections, global power interconnection.

http://dx.doi.org/10.38028/esr.2020.04.0008

This is an open access article under a Creative Commons Attribution-NonCommercial 4.0 International License.

C) 2020 ESI SB RAS and authors. All rights reserved.
5. Reliability of fuel and energy supply to consumers, energy security.

6. Power quality.

More information is available on the Conference website: http://isem.irk.ru/energy 21

Having discussed the reports and papers on the development, functioning, and transformation of the energy sector, the Conference states the following:

The ongoing global technological transformation of energy systems is both a challenge and a window of great opportunities for Russia that must be used to ensure the efficiency, availability, and environmental friendliness of energy supply systems. Innovative equipment and technologies, including their smartization, radically change the properties of energy systems, which increases the level of their efficiency, controllability, stability, survivability, and at the same time creates new problems in the functioning of these systems due to changes in their properties. The technological transformation of the energy sector brings about new challenges in managing and controlling the operation and expansion of energy systems, which requires in-depth fundamental studies with the scientific community playing a major role in their organization and implementation.

Electric power integration is one of the dominant global trends, providing significant systems effects to its participants. The Russian electric power system is one of the largest in Eurasia and the world. It acts as an essential participant in such integration and interacts with the energy systems of neighboring countries. One of the serious problems is the electric power reintegration in the post-Soviet space, in particular, the reintegration of Russia, Central Asia, and the Caucasus with joint access to the electricity markets of the Middle East, Asia Minor, and South Asia. The process of establishing an interstate power interconnection in Northeast Asia is becoming increasingly more practically realizable, in which Russia, based on the 
regions of Siberia and the Far East, can also become a noticeable player while receiving economic benefits.

A big socio-economic problem of Siberia and the Russian Far East is a low level of income, which cannot compensate for the harsh natural and climatic living conditions for the population, and leads to its decline in these regions.

The policy of science and technology development of Russia, including its eastern regions, should provide for mechanisms to integrate into the chain of added values not only of exports of energy resources but also of the expansion of energy systems providing appropriate conditions for the population and the growth of production of goods and services, based on innovative and environmentally sound technologies.

The comprehensive and priority development of Siberia and the Far East's territories is recorded in some of the strategic state documents: Presidential Address to the Federal Assembly, 2020; Energy Security Doctrine of the Russian Federation (approved by the Decree of the President of the Russian Federation of May 13, 2019, No. 216); Energy strategy of the Russian Federation until 2035 (approved by the Order of the Government of the Russian Federation dated June 9, 2020, No. 1526-r). Conversion to gas in East Siberia and the Far East is one of the prime objectives for developing national energy and economy and addressing social problems in these regions.

The main problems in local power supply systems, which are commonplace in the East of the Russian Federation, are associated with the underdevelopment of the transport infrastructure and the unsatisfactory state of energy sources, which leads to high values of energy tariffs and budget subsidies allocated to compensate for the lost revenues of energy producers.

The environmental problems of the territories of special nature management (for example, the Central Ecological Zone of the Baikal Natural Territory) are caused by the high share of coal in the fuel balance, the predominance of low-efficiency small-capacity boiler houses, the lack of equipment for cleaning exhaust gases and high heat losses in the heat supply systems of consumers.

Under the current conditions of the operation and expansion of energy systems, their reliability and energy security issues have become of particular relevance. This is due to a lack of investment in the industry, high wear and tear of production assets, significant depletion of existing oil and gas fields, the need to develop new, much more expensive oil and gas fields in the harsh climatic conditions of the Arctic zone, and low prices for hydrocarbons in world markets. The excessive amount of old emergency prone generating capacities remains an unresolved issue, which negatively affects both the reliability of the power supply and the price of electricity. In the practice of managing the expansion of power systems, the energy security requirements are still not taken into account. The issues of a comprehensive approach to management and interrelated development of energy industries within the national energy sector, as well as the improvement in the quality of training of qualified personnel for the energy sector, remain highly topical. The lack of domestic efficient generating equipment and the use of foreign generating equipment in the domestic power industry often leads to problems with the power supply to large power regions, in particular, due to the incompatibility of settings for the operating parameters of foreign equipment and the specified disturbances of domestic power systems.

Based on the delivered presentations, exchange of views, and conclusions of discussion, the Conference recommends the following:

Given the considerable socio-economic importance of the energy issues under consideration and the attained high theoretical and practical level of their study, the recommendations formulated for the executive branch authorities are as follows:

1. It is necessary to immediately start to implement, on a permanent basis, the objectives set in the Federal Law "On Strategic Planning in the Russian Federation" of 28.06.2014 N 172), which regulates the relations arising between participants in strategic planning in the process of goal-setting; forecasting; planning and programming of socio-economic development of the Russian Federation, the subjects of the Russian Federation and municipalities, economic sectors and areas of state and municipal governance; ensuring national security of the Russian Federation; as well as monitoring and controlling the implementation of strategic planning policy documents.

2. To meet the objectives at the federal, regional, and municipal levels, as stipulated by the Federal Law "On Strategic Planning," strategic directions for the expansion of energy systems at the corresponding level shall be established and regularly updated. The methodological basis for achieving such objectives is the theory and methods of the systems analysis of energy development, while the scientific tools should be based on domestic technologies and ensure the completeness and integrity of the information base to perform the functions of strategic planning, development, and updating of energy policy, and monitoring of the implementation of strategic and policy decisions in the management of energy development at each level of the hierarchy of governmental authorities in the Russian Federation. It is necessary to develop mechanisms to translate systems efficient solutions for energy development from the upper levels of government to the level of individual energy companies owned by different entities.

3. Planning the development of Russia's energy industries should place emphasis on ensuring the reliability of fuel and energy supplies to consumers, given the most important requirements of energy security 
of Russia under various energy sector operating conditions. Elaborating the issues of the development of the energy industries of the Russian Federation, one should employ the expertise in integrated research and systems analysis as gained in specialized scientific organizations, particularly in the Russian Academy of Sciences (including the Melentiev Energy Systems Institute, SB RAS)

4. Currently, Russia has completed a complex and timeconsuming (years-long) stage of work on the formation of a large number of policy documents defining the strategic development of the economy and energy in the East of the country to 2030-2035, taking into account the energy cooperation of Russia with the countries of the Asia-Pacific Region (APR). The stage of 2036 to 2050 is conceptually significant. This is the stage of innovative development of the Russian energy sector characterized by a transition to fundamentally different technological capabilities of highly-efficient use of conventional energy resources and new energy sources, as well as by the emergence of the prosumer.

5. The prime objective should be to develop a scientificallybased strategy (roadmap) for long-term (to the year 2050) innovative development of the energy sector of the country and its eastern regions in the context of the objective inevitability of the paradigm shift in energy cooperation between Russia and the APR countries: the transition from energy trade to innovative and technological cooperation. Such a strategy can be developed only relying on the close cooperation of teams of research and design institutes, companies, banks, and others, with the active support on the part of the Government of the Russian Federation and regional authorities.

6. To promote the conversion of Siberia and the Russian Far East to gas, it is necessary to coordinate the activities of executive branch authorities of federal subjects of Russia and domestic business; define the powers and obligations of the parties; develop relevant regional conversion-to-gas programs; design public-private partnership schemes to ensure reliable funding of the construction of main and regional transport pipeline infrastructure. It is also essential to provide regulatory documents and other enactments on social guarantees for the citizens in terms of compensation for the costs they incurred when switching to gas.

7. It is necessary to actively conduct comprehensive research into energy (electric power, oil energy, gas energy) integration of Russia within the existing and emerging interstate energy interconnections in Eurasia, including those in the former Soviet Union, in Northeast Asia, and other areas, with the participation of Russian and foreign organizations.

8. There is an urgent need to formulate a comprehensive program for the development of local energy in Russia's East, including the Arctic regions and areas of new development, with a focus on maximizing the efficiency and reliability of energy supply through diversification of energy production, including the transition to alternative energy sources (liquefied natural gas, crude oil, and coal from local fields), small-capacity nuclear power plants, and renewable energy sources.

9. Implementation of a project to build small- and medium-capacity nuclear power plants will make it possible to reduce greenhouse gas emissions while developing domestic energy technologies that have a powerful multiplier effect and high export potential. The presence of the IAEA-supervised small nuclear power system facilities with high integral safety in the Eastern and Arctic regions will serve as a basis for solving the social, economic, environmental, and geostrategic development problems of Russia.

10. At present, the only feasible way to make heat generation in the Central Ecological Zone of the Baikal Natural Territory more environmentally sound is to use electricity for heating purposes. The implementation of this direction requires a revision of the list of activities prohibited within the zone; development and approvement of special tariff solutions aimed at compensating revenue shortfalls of heat and electricity producers, as well as a substantial modernization of the electric grid infrastructure.

11. As part of the work to determine the regulatory reserve of generating capacity, one should justify the regulatory values of the probabilistic criterion for the adequacy of the Unified Power System of Russia and off-grid power systems and ensure its adoption in the practice of managing the expansion of the Unified Power System of Russia and off-grid power systems.

12. It is necessary to initiate comprehensive research works on the systems analysis of the reliability issues of fuel and energy supply to consumers under various operating conditions of the energy sector and energy systems in the future up to the year 2035, taking into account the interrelated operation of energy industries within the energy sector of the country with a scientific justification of the relevant measures.

13. It is necessary to establish the directions for systematic improvement in the education system to train highly qualified personnel for the domestic power industry.

14. Based on the results, the Conference decided to send this document to the leading Russian publications in the field of energy, relevant ministries and agencies of the Russian Federation, energy companies of the Russian Federation, the administrations of the eastern regions of Russia, and foreign and international organizations. 